\title{
Optic disc anomalies and frontonasal dysplasia
}

P Hodgkins, M Lees, J Lawson, W Reardon, J Leitch, P Thorogood, R M Winter, D S I Taylor

Department of

Ophthalmology, Great

Ormond Street

Hospital for Children,

Great Ormond Street,

London WC1N 3JH

P Hodgkins

J Lawson

J Leitch

D S I Taylor

Department of Clinical Genetics, Great

Ormond Street

Hospital for Children,

Great Ormond Street,

London WC1N 3JH

M Lees

W Reardon

R M Winter

Developmental Biology Unit, Institute of Child Health, 30 Guildford

Street, London

WC1N 1EH

P Thorogood

Correspondence to:

Mr D S I Taylor.

Accepted for publication

29 September 1997

\section{Abstract}

Aims-To document the optic disc abnormalities in patients with frontonasal dysplasia in association with basal encephalocele.

Methods-Names and hospital numbers of patients with midline clefts were obtained from the ophthalmology and genetics database. Six patients were identified who had the following common findings: midline facial cleft with midline cleft lip and palate; hypertelorism; absent corpus callosum; basal (sphenoethmoidal) encephalocele; and pituitary deficiency (five out of six cases). Ophthalmic examination was performed with fundal photography where possible.

Results-Two patients had unilateral and one a bilateral peripapillary staphyloma. Two patients had bilateral optic disc hypoplasia and one appeared to have a peripapillary staphyloma in one eye and a morning glory disc in the other.

Conclusion-Optic disc abnormalities were found in all patients with this constellation of clinical findings. This association appears to represent a distinct subgroup within the spectrum of frontonasal dysplasia. The presence of midline facial anomalies and any dysplastic disc should alert the physician as to the presence of an encephalocele.

(Br f Ophthalmol 1998;82:290-293)

Frontonasal dysplasia was a term suggested by Sedano et $a l^{1}$ in 1970 to describe a group of patients with midline facial clefting. It has a wide clinical spectrum in which there may be marked hypertelorism, primary telecanthus, a broad nasal tip which is frequently cleft, median cleft upper lip and premaxilla, median cleft palate, anterior or basal encephalocele, and agenesis of the corpus callosum. These abnormalities can be present in any combination or severity although hypertelorism is a constant feature. The pathogenesis is unknown but it is possible that a primary neural crest migration defect or a fetal ischaemic episode inhibiting cell migration is the initial event. ${ }^{2} \mathrm{~A}$ "non-separation" theory which assumes that, during closure of the neural tube, the ectodermal elements fail to separate or that the craniopharyngeal canal persists have also been proposed to account for the variety of clinical signs. ${ }^{3}$ Most cases are sporadic although rare familial cases ${ }^{4}$ have been described in a patient with frontonasal dysplasia.

The association of midline clefting with basal (sphenoethmoidal) encephalocele and optic disc abnormalities seems to represent a distinct subgroup of frontonasal dysplasia. It is rare for optic disc abnormalities to occur in the median facial cleft syndrome in the absence of an encephalocele. Some authors have defined this entity as part of the facial clefting syndromes. ${ }^{5}$ The optic disc abnormality described in the majority of these cases is of the morning glory type.$^{6-12}$ However, peripapillary staphyloma $^{13}{ }^{14}$ and optic disc hypoplasia have also been described ${ }^{14}{ }^{15}$ with this association.

We have reviewed the ophthalmological findings in six cases of midline craniofacial clefting seen at Great Ormond Street Hospital for Children in the past 10 years to document the optic disc abnormalities and discuss their possible embryological origin. The general clinical details of these cases are discussed elsewhere. ${ }^{16}$

\section{Material and methods}

The names and hospital numbers of patients seen at Great Ormond Street Hospital with midline facial clefting were located from the databases for the departments of ophthalmology and clinical genetics. The notes and facial photographs, where possible, were reviewed.

\section{Results}

Six patients were identified who had the following common findings: midline facial cleft

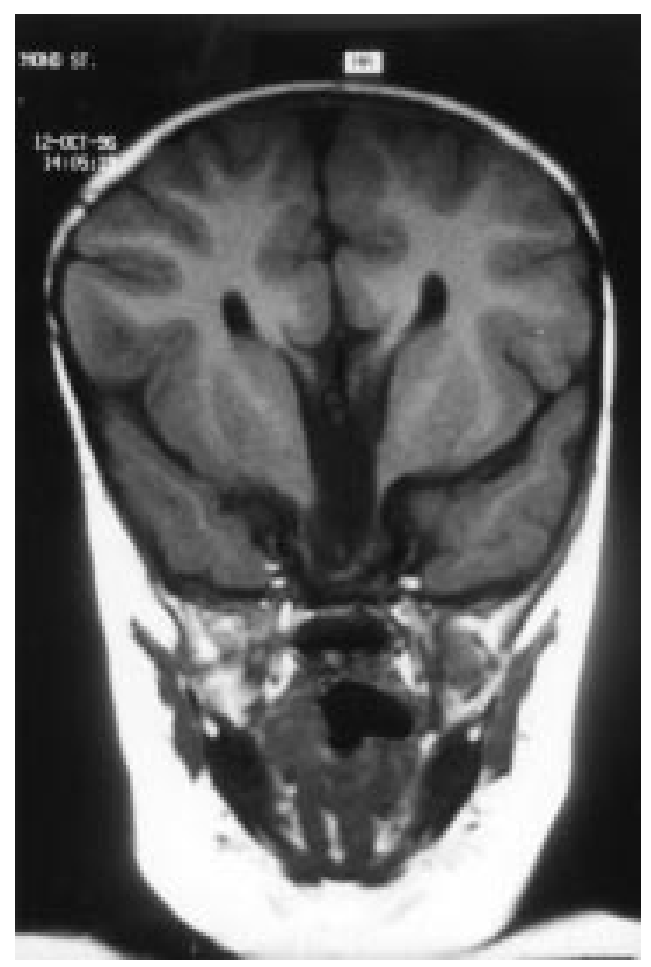

Figure 1 Magnetic resonance imaging scan clearly showing basal encephalocele pushing down between the optic nerves. 
Table 1 Summary of ophthalmic findings

\begin{tabular}{|c|c|c|c|c|c|c|c|}
\hline Case & Eye & Visual acuity & Ultrasound scan & Size of optic disc & Fibroglial tissue & Vascular pattern & Pigmentation \\
\hline \multirow[t]{2}{*}{1} & Right & $6 / 9$ & Normal & Normal & NA & Normal & Nil \\
\hline & Left & $6 / 60$ & Deep excavation & Normal & Absent & $\begin{array}{l}\text { Normal from disc, sharp } \\
\text { bend over edge }\end{array}$ & $\begin{array}{l}\text { Walls with RPE } \\
\text { change }\end{array}$ \\
\hline \multirow[t]{2}{*}{2} & Right & $6 / 18$ & Deep excavation & Normal & + present & \multirow{2}{*}{$\begin{array}{l}\text { Normal from disc, sharp } \\
\text { bend over edge for both } \\
\text { eyes }\end{array}$} & \multirow{2}{*}{$\begin{array}{l}\text { Both with RPE change } \\
\text { in walls of depression }\end{array}$} \\
\hline & Left & $6 / 18$ & Deep excavation & Normal & Absent & & \\
\hline \multirow[t]{2}{*}{3} & Right & $6 / 9$ & Normal & Small & NA & Normal & Nil \\
\hline & Left & $6 / 18$ & Normal & Small & NA & Normal & Nil \\
\hline \multirow[t]{2}{*}{4} & Right & $6 / 9$ & Normal & Normal & NA & Normal & Nil \\
\hline & Left & $3 / 60$ & Deep excavation & Normal & Absent & $\begin{array}{l}\text { Normal from disc, sharp } \\
\text { bend over edge }\end{array}$ & $\begin{array}{l}\text { Walls with RPE } \\
\text { change }\end{array}$ \\
\hline \multirow[t]{2}{*}{5} & Right & $6 / 9$ & Normal & Small & NA & Normal & Nil \\
\hline & Left & $6 / 9$ & Normal & Small & NA & Normal & Nil \\
\hline \multirow[t]{2}{*}{6} & Right & $6 / 18$ & Deep excavation some tissue & Slightly enlarged & + present & $\begin{array}{l}\text { Sharp bend over edge, slight } \\
\text { radiality }\end{array}$ & $\begin{array}{l}\text { RPE change in walls of } \\
\text { depression }\end{array}$ \\
\hline & Left & HM & $\begin{array}{l}\text { Shallow excavation with } \\
\text { tissue within it }\end{array}$ & Enlarged & +++ present & $\begin{array}{l}\text { Abnormal radial } \\
\text { configuration }\end{array}$ & $\begin{array}{l}\text { Peripapillary annulus } \\
\text { RPE change }\end{array}$ \\
\hline
\end{tabular}

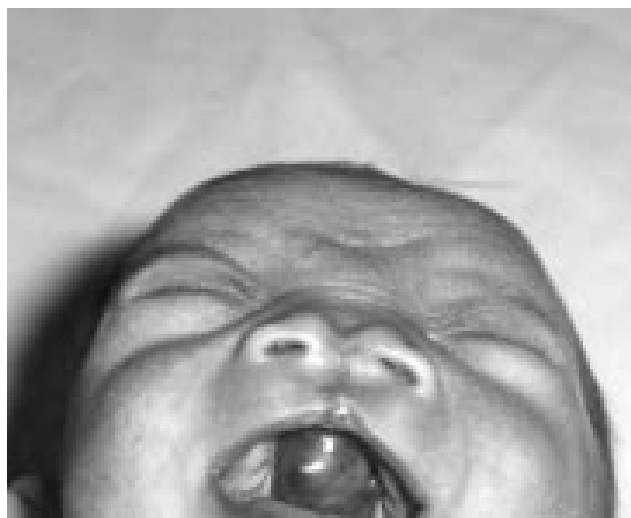

Figure 2 Encephalocele visible in the roof of the mouth. Cleft nose and hypertelorism. Note normality of each individual nostril.

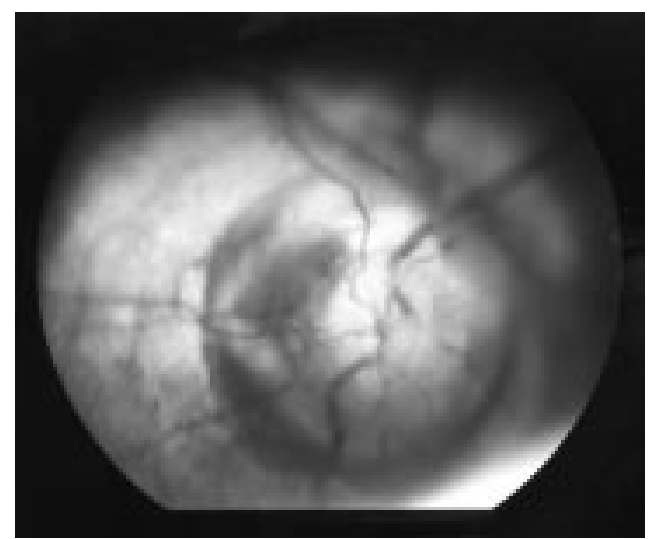

Figure 3 Peripapillary staphyloma. Deep excavation with a relatively normal papilla in the base.

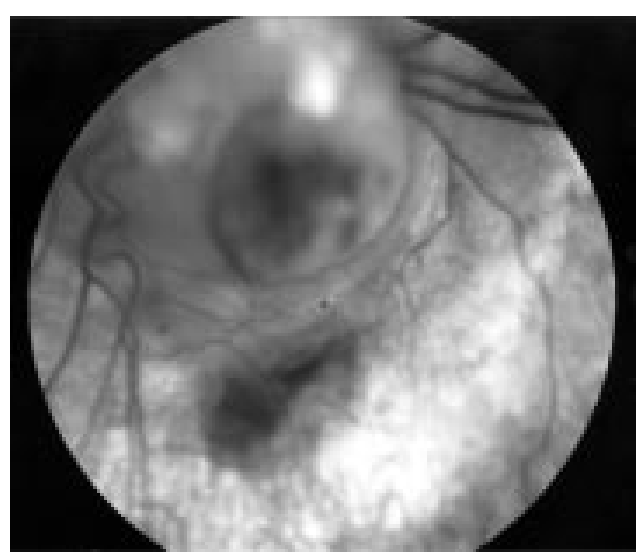

Figure 4 Abrupt edge to a deep peripapillary staphyloma. with midline cleft lip and palate; hypertelorism; absent corpus callosum; basal (sphenoethmoidal) encephalocele and pituitary deficiency (five out of six cases). Ophthalmic examination was performed with fundal photography where possible and a summary is found in Table 1.

\section{Discussion}

We describe six patients with midline facial clefts and basal (sphenoethmoidal) encephalocele (Fig 1) all of whom had optic disc abnormalities. The midline clefting (Fig 2) appears to be similar to that described by previous authors. ${ }^{6-15}$

In the first three cases fundal examination revealed a deep depression of the posterior pole with a relatively normal appearing papilla in the base. Two of the cases were unilateral and one bilateral. There was no accumulation of prepapillary glial tissue and the walls and edges of the staphylomas showed alterations in the choroid and retinal pigment epithelium (Fig 3). The margins were abrupt and irregular (Fig 4) and the retinal vessels had a normal pattern curve when passing through it. The appearances were consistent with peripapillary staphyloma. This condition is distinguished from morning glory disc by its greater depth, the absence of prepapillary and peripapillary vascular and glial alterations and the presence of a relatively normal optic disc in the base. Peripapillary staphyloma is usually an isolated malformation and this seems to be one of the few CNS malformations that can give rise to it.

In case 4 (Fig 5) there was a morning glory type optic disc anomaly in the left eye with an enlarged disc, glial tissue at the centre, a radial vessel pattern, and a surround of chorioretinal pigment change. In the right eye there was more of a peripapillary staphyloma appearance with a far deeper excavation although there was a radial pattern to the vessels and a small amount of glial tissue.

Morning glory disc is a term introduced by Kindler $^{17}$ consisting of an enlarged excavated disc with fibroglial appearing tissue at its centre, an elevated subretinal peripapillary annulus of chorioretinal pigmentary change, and abnormal vessels radiating outwards. This congenital anomaly was likened to the withering morning glory flower from which it derives its name. A spectrum of changes have been 


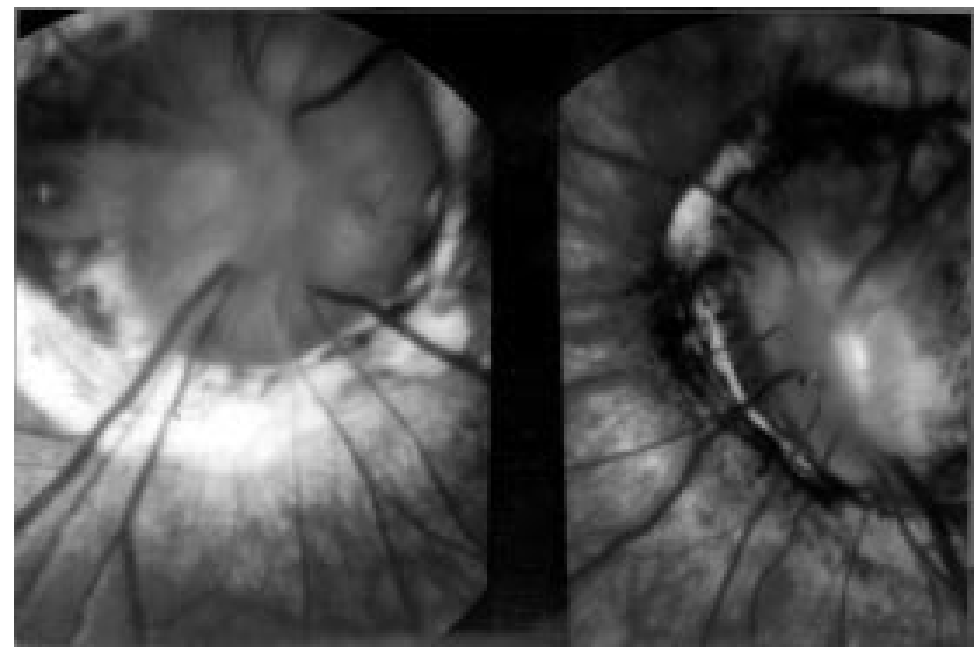

Figure 5 Left eye shows an enlarged disc, glial tissue in the centre, a radial vessel pattern, and a surround of chorioretinal pigment change. The right eye shows more of a perpapillary staphyloma appearance with a deeper excavation and far less glial tissue.

described in the morning glory disc. ${ }^{18} 19$ Peripapillary staphylomas are not commonly associated with other ocular or systemic anomalies $^{20}$ although there are reports of its association with midline clefting problems. ${ }^{13}{ }^{14}$ Brodsky et $a l^{14}$ have also described atypical retinochoroidal coloboma in five patients with dysplastic discs and transsphenoidal encephalocele. We found this to be present in only one of our cases.

The relatively normal appearance of the disc and vessels in peripapillary staphyloma suggest that the development of these structures is complete before the onset of the staphylomatous process. ${ }^{21}$ Pollock $^{21}$ has argued that the clinical features of peripapillary staphyloma are most consistent with diminished peripapillary structural support perhaps resulting from incomplete differentiation of sclera from the posterior neural crest cells or a neural migration problem. However, in addition to these classic descriptions of peripapillary staphyloma and morning glory disc, intermediate forms have been observed. ${ }^{22}$

In cases five and six there was a bilateral optic disc hypoplasia (Figs 6 and 7). This is known to be associated with midline problems as in de Morsier's syndrome of septo-optic dysplasia. It has also been described in frontonasal dysplasia ${ }^{15}$ and in patients with midline clefting and basal encephaloceles. ${ }^{14}$ Optic nerve hypoplasia is a condition which results from an excessive loss of ganglion cell axons from the optic nerve before its full development. This can occur as a result of an insult anywhere along the developing visual system from the retinal ganglion cell to the visual cortex. ${ }^{23}$ Hot and Good ${ }^{24}$ have highlighted the problem in deciding if the condition is really a primary optic nerve hypoplasia or a very early optic atrophy. In fact when the degree of hypoplasia is reviewed in Figure 6 the disc is quite hypoplastic suggesting an earlier insult than in Figure 7 where the disc is less hypoplastic but also shows band atrophy.

We have therefore observed combined clinical characteristics of: absent corpus callosum;

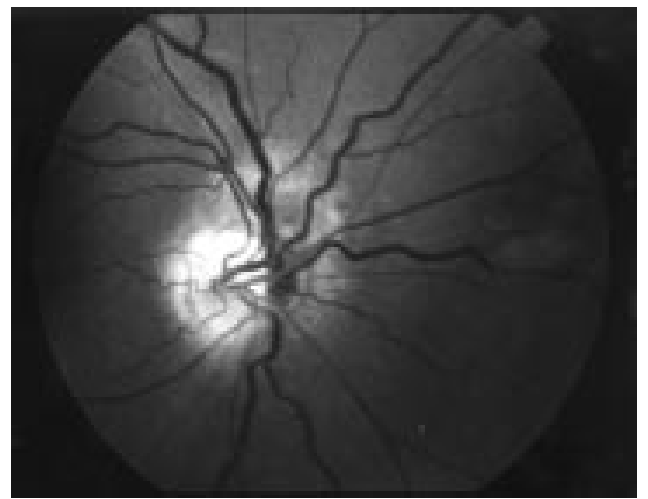

Figure 6 Band atrophy with optic nerve hypoplasia.

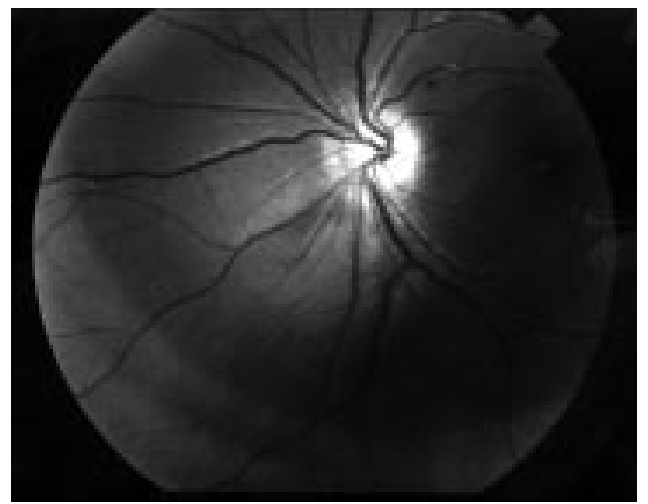

Figure 7 Moderately severe optic nerve hypoplasia.

cleft palate and lip; sphenoethmoidal encephalocele; and pituitary problems in association with more than one type of optic disc anomaly. This would suggest the embryological origins of these disc abnormalities may not be so dissimilar. The various clinical features described probably represent secondary consequences as a result of a cascade of disruption to normal development with the likely primary event disruption of the morphogenesis of the frontonasal process. Itakura et $a l^{11}$ have suggested that if the sphenoid encephalocele prevents fusion of the palate, which precedes formation of the optic nerve, then the later development of the optic nerve could be abnormal. However, the variability of the optic disc abnormalities in these cases is difficult to ascribe to a single cause and seems likely to result from the interplay of several different factors:

(1) The exact timing in development when the insult occurs.

(2) The nature, duration, and intensity of the insult.

(3) The exact position and size of the resulting encephalocele. Reviewing the computed tomogram and magnetic resonance image did not reveal any obvious difference in encephalocele size or position to account for the differing clinical appearances. Small positional differences that are crucial very early in development may become undetectable after birth.

(4) Mechanical dragging or tethering of the optic nerve as the face grows leading to a peripapillary staphyloma or morning glory disc. 
(5) A physical obstruction and resulting pressure effect caused by the encephalocele leading to secondary death of axons and optic nerve hypoplasia.

In summary, we found optic disc abnormalities in all our patients with midline facial clefting and basal encephalocele. The changes consisted of a spectrum including peripapillary staphyloma, morning glory disc, and optic nerve hypoplasia. The presence of midline facial anomalies - for example, cleft lip or palate with any dysplastic optic disc anomalies, should alert the physician to the presence of a basal encephalocele. Hypertelorism is usually present but may be mild and inconspicuous. This association appears to represent a distinct subgroup within the spectrum of frontonasal dysplasia.

1 Sedano HO, Cohen MM, Jirasek J, et al. Frontonasal dysplasia. F Pediatr 1970;76:906-13.

2 Cohen MM, Sedano HO, Gorlin RJ, et al. Frontonasal dysplasia (median cleft face syndrome): comments on aetiology and pathogenesis. Birth Defects 1971;7:117-19.

3 Yokota A, Matsukado Y, Fuwa I, et al. Anterior basal encephalocele of the neonatal and infantile period. Neurosurgery 1986;19:468-78.

4 Mazzola RF. Congenital malformations in the frontonasal area. Their pathogenesis and classification. Clin Plast Surg 1976;3:573.

5 Tessier P. Anatomical classification of facial, craniofacial and latero-facial clefts. Maxillofacial Surg 1976;4:69.

6 Pollock JA, Newton TH, Hoyt WF. Transsphenoidal and transethmoidal encephaloceles. A review of clinical and transethmoidal encephaloceles. A review of clinical and
roentgen features in eight cases. Radiology 1968;90:442-53.

7 Koenig SB, Naidich TP, Lissner G. The morning glory syndrome associated with sphenoidal encephalocele. Ophthal-

8 Caprioli J, Lesser RL. Basal encephalocele and morning glory syndrome. Br F Ophthalmol 1983;67:349-51.
9 Hope-Ross M, Johnston SS. The morning glory syndrome associated with sphenoethmoidal encephalocele. Ophthalassociated with sphenoethmoidal enc
mic Paediatr Genet 1989;11:147-53.

10 Grubben C, Fryns JP, De Zegher F, et al. Anterior basal encephalocele in the median facial cleft syndrome. Comments on nosology and treatment. Gen Counselling 1990;38:103-9.

11 Itakura T, Miyamoto K, Uematsu Y, et al. Bilateral morning glory syndrome associated with basal encephalocele. $\mathcal{f}$ Neurosurg 1992;77:949-51.

12 Eustis HS, Sanders MR, Zimmerman T. Morning glory syndrome in children. Associations with endocrine and central nervous system anomalies. Arch Ophthalmol 1994; 112:204-7.

13 Walsh FB, Hoyt WF. In: Clinical neuro-ophthalmol. 3rd ed. Baltimore: Williams \& Wilkins, 1969.

14 Brodsky MC, Hoyt WF, Hoyt CS, et al. Atypical retinochoroidal coloboma in patients with dysplastic optic discs and Transsphenoidal encephalocele. Arch Ophthalmol 1995;113:624-8.

15 Roarty JD, Pron GE, Siegel-Bartelt J, et al. Ocular manifestations of fronto-nasal dysplasia. Plast Reconst Surg 1994;93:25-30.

16 Lees MM, Hodgkins P, Reardon W, et al. Oculo-encephalofrontonasal dysplasia. Clin Dysmorphol 1998 (submitted).

17 Kindler P. Morning glory syndrome: unusual congenital optic disc anomaly. Am f Ophthalmol 1970;69:376-84.

18 Beyer WB, Quencer RM, Osher RH. Morning glory syndrome: a functional analysis including fluorescein angiography, ultrasonography and computerized tomography.

19 Traboulsi EI, O'Neil JF. The spectrum in the morphology of the so called "morning glory disc anomaly". F Pediatr Ophthalmol Strabismus 1988;25:93-8.

20 Villanga Gornes P, Terraza AG, Gil-Gibernau JJ. Ophthalmoscopic evolution of papillary malformations. F Pediatr Ophthalmol Strabismus 1995;32:20-5.

21 Pollock S. The morning glory disc anomaly: contractile movement, classification and embryogenesis. Doc Ophthalmol 1987;65:439-60.

22 Rodrigo J, Gil Gibernau JJ, Galan Terraza A. Colobomas: evolution and complications. Stud Ophthalmol 1985;4:2740.

23 Novakovic P, Taylor D, Hoyt W. Localising patterns of optic nerve hypoplasia - retina to occipital lobe. Brf Ophthalmol 1988;72:176-9.

24 Hoyt CS, Good WV. Do we really understand the difference between optic nerve hypoplasia and atrophy. Eye 1992;6: 201-4. 